\title{
O Dossiê Henri Lefebvre e a problemática urbana na Geousp
}

Em 2018, teve lugar nas dependências do Departamento de Geografia da Universidade de São Paulo o curso de extensão intitulado "Henri Lefebvre e a problemática urbana", com sete aulas de três horas, tendo cada uma sido ministrada por um professor na noite de um dia da semana (com exceção das duas que encerraram o curso na manhã de 11 de agosto, um sábado). De iniciativa do Grupo de Estudos de Geografia Urbana Crítica Radical (Gesp), o curso foi programado no fluxo de celebrações dos 50 anos da primeira edição de $O$ direito à cidade, procurando trazer uma ampla e diversa reflexão sobre nossa condição urbana a partir dos escritos de Henri Lefebvre. Os artigos reunidos aqui e que dão origem ao "Dossiê Henri Lefebvre e a problemática urbana" são resultados das reflexões que conduziram cada uma das aulas. Os artigos são assinados pelos próprios professores e trazem o movimento debatido na ocasião, a respeito dos quais é possível fazer algumas considerações.

Uma das importantes contribuições de Henri Lefebvre

\section{revista}

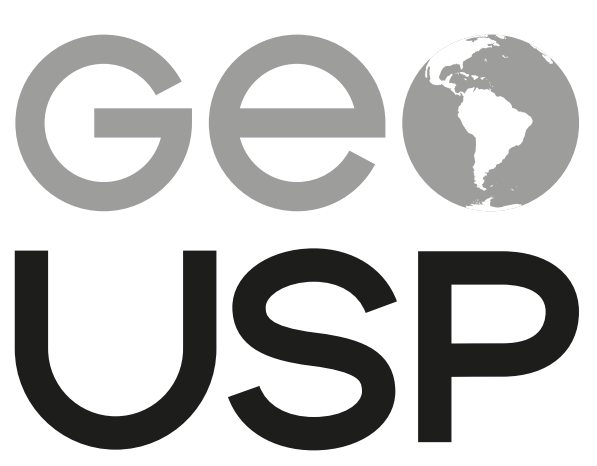

espaço e tempo

Volume $23 \cdot n^{\circ} 3$ (2019)

ISSN 2179-0892 foi iluminar os conteúdos do novo período histórico que se esboçava no final dos anos 1960: a sociedade urbana anunciando a crise da história e do pensamento historiador. Saída do processo de industrialização, a urbanização deixava de estar submetida à lógica da indústria e à sociedade industrial. Nesse momento, também se rompiam os laços com o passado, assinalando a passagem da historicidade à espacialidade.

No movimento de construção de um pensamento crítico, a obra de Lefebvre percorre o século XX como crítica teórica e como crítica das relações sociais que se reproduzem no capitalismo, o que fundamenta a antecipação de temas do século XXI e o rigor de um projeto utópico-revolucionário. Em sua obra, Lefebvre rejeita o acabado, o imóvel, e propõe uma crítica radical do presente visando a construção de um caminho que permita pensar um outro mundo. A exigência é 


\section{revista}

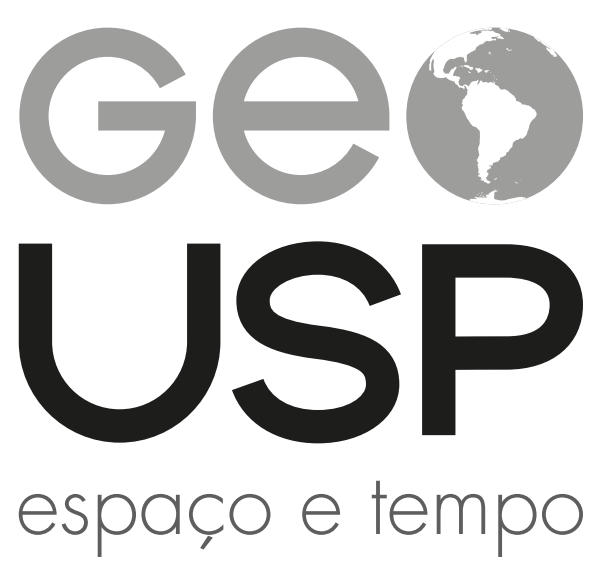

Volume $23 \cdot n^{\circ} 3$ (2019)

ISSN 2179-0892 mergulhar na compreensão das contradições presentes e de seus fundamentos impostos pela lógica capitalista.

No plano teórico, o movimento do pensamento de Henri Lefebvre caminha na superação da filosofia em direção à constituição do que chama de metafilosofia. Nesse percurso, a contundente crítica a uma filosofia que se descola da práxis é estendida também às ciências parcelares que fragmentam a totalidade social. No plano da práxis, o movimento vai da historicidade à espacialidade. Assim, no percurso de um pensamento que pretende construir uma compreensão do mundo como totalidade aberta e dialética, o conteúdo dado pelo momento histórico revela que as relações de produção que sustentam o capitalismo se reproduzem por meio da produção do espaço. Para Lefebvre, uma nova realidade aponta uma nova problemática: a realidade urbana que é, em essência, espacial.

No movimento mais amplo que perpassa a organização do Dossiê, importantes temas e aspectos do pensamento lefebvriano são articulados numa linha de desenvolvimento que envolve os seis artigos.

No primeiro, Carlos esboça o pensamento de Henri Lefebvre sobre a cidade e o urbano situando, por um lado, o urbano no pensamento de Lefebvre a partir do movimento de passagem da historicidade à espacialidade e, por outro, o "direto à cidade", que projeta o pensamento e a ação para o futuro como momento de construção do homem total. Nesses termos, a dimensão utópica do pensamento lefebvriano se apresenta como a tradução do movimento do pensamento que projeta a sociedade urbana como real e virtual. Nessa proposta de leitura, o "direto à cidade" sinaliza o prolongamento da utopia marxista como o negativo do direito tornado política pública.

No segundo artigo, Faleiros de Pádua entende que no momento atual a urbanização apresenta-se como uma questão fundamental na compreensão da realidade. Ao mesmo tempo em que se conduz pelas determinações da acumulação crítica do capital, as contradições revelam a vida urbana em crise e as necessidades radicais que emergem daí com força. Nesse sentido, a redução do habitar ao habitat, com a funcionalização e instrumentalização do 


\section{revista}

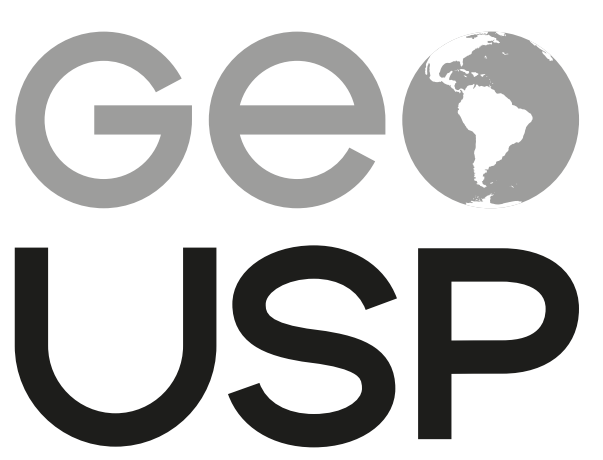

\section{espaço e tempo}

Volume $23 \cdot n^{\circ} 3$ (2019)

ISSN 2179-0892 espaço e da vida cotidiana, pode, contraditoriamente, apontar as possibilidades que se colocam como luta pelo espaço, pela apropriação concreta do urbano em constituição e pela reconquista do habitar.

Para Alvarez, a descoberta da produção social do espaço, que em si já não é trivial, permitiu um salto teórico crucial na interpretação da sociedade contemporânea. É a captura da dimensão espacial pelos processos de acumulação do capital e pela racionalidade do Estado, no entanto, que coloca a produção do espaço simultaneamente na escala mundial e sob o comando de processos mais ou menos homogeneizantes, modificando profundamente sua natureza. $\bigcirc$ elemento conceitual que compreende essa transfiguração no argumento da autora é o de "mobilização do espaço", que aparece no título do artigo e que permite desacoplar a leitura que se pôde fazer do espaço em outros momentos daquela que se exige atualmente.

A leitura de Volochko se debruça sobre o modo como Lefebvre trabalha a noção de totalidade, como essa noção articula a filosofia e a ciência a partir da dialética e como ela aparece em alguns momentos de modo mais ou menos explícito em seus textos. Se essa noção-démarche enlaça várias outras (muitas das quais vêm de Marx), o desafio seria justamente entender como podemos trabalhar com o espaço e o urbano como totalidades nas ciências humanas. Assim se formula a questão: como Lefebvre desdobra para o espaço (plano da realidade da produção do espaço) e para a teoria (procedimentos metodológicos e analíticos) a noção de totalidade dialética (aberta, movente)?

Simoni Santos apresenta aspectos da morfologia do pensamento dialético lefebvriano marcando a especificidade radical que faz parte da forma como o próprio Lefebvre reelabora o material que herdou para compor novas bases para o pensamento crítico. Para o autor, frequentemente o trabalho de Henri Lefebvre é admitido como extensão capaz de iluminar o pensamento de Marx ou como uma porta de entrada para compreender a dialética, mas essa via é arriscada. Um desses riscos é tratar a dialética lefebvriana como continuidade imediata e aplicação rigorosa do que já estava inscrito em Marx. A nem tão pouco usual identificação das 


\section{revista}

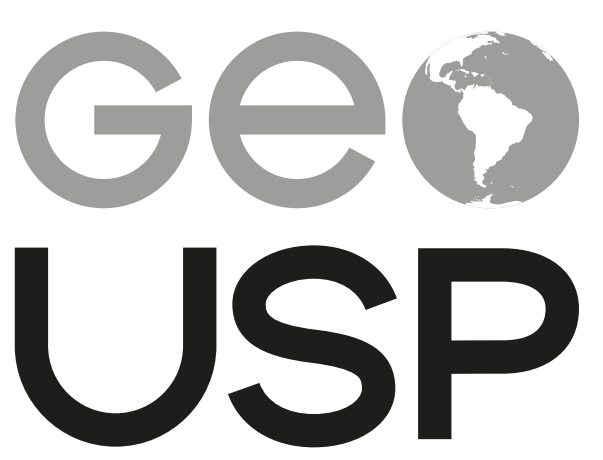

\section{espaço e tempo}

Volume $23 \cdot n^{\circ} 3$ (2019)

ISSN 2179-0892 tríades de Lefebvre com a estrutura triádica da dialética hegeliana é outro.

$\bigcirc$ artigo de Alves avança na compreensão da composição triádica do pensamento lefebvriano no que tange à problemática urbana. Frente a um mundo onde o processo de reprodução do capital parece avassalador e o espaço é um dos elementos de sua reprodução, o que fica mais evidente em momentos de crise da reprodução capitalista, torna-se fundamental entender o processo de produção desse espaço. Nessa direção, pretende-se debater conceitualmente as dimensões da tríade lefebvriana concebido/percebido/vivido.

Espera-se que, no conjunto, o Dossiê possa contribuir para o debate conceitual, nas questões de método e no âmbito teórico com as reflexões trazidas nesse grande esforço coletivo. $\bigcirc$ trabalho aqui reunido e organizado resulta de um caminho de leitura das obras de Henri Lefebvre que remonta aos anos 1970-80, cujo início foi marcado pela força do movimento que deu origem à chamada geografia crítica e quando um grupo de professoras do Departamento de Geografia da USP se reuniu em torno da leitura das obras de Marx e Lefebvre no grupo de estudos coordenado por José de Sousa Martins.

A leitura atenta das obras de Lefebvre e a atualidade de seu pensamento encontrou campo fértil na Geografia da FFLCH/USP. Um dos resultados dessa união foi a criação do Gesp, em 2001, e a produção de uma coleção de livros sobre a problemática urbana vista de diferentes óticas. Tendo assumido o rótulo de uma geografia "marxista-lefevriana", a coleção tem continuidade aqui, com as reflexões de alguns membros do grupo sobre a obra de Lefebvre a respeito da cidade e do urbano (logo, do espaço) em sua atualidade para pensar o século XXI.

Imersos na banalização oriunda do pragmantismo que assola a universidade, o pensamento perde sua potência reveladora do mundo e de nossa condição no mundo. No âmbito acadêmico, o estreitamento do tempo da reflexão infligido por parâmetros produtivistas pretende dominar a pesquisa. A homogeneidade se impõe contra o que difere. $\bigcirc$ preconceito contra a teoria e a teorização imposto pela velocidade do produtivismo ganha adeptos dentro da academia. Os parâmetros quantitativos e a volta da censura concorrem para a produção 
de um conhecimento ideológico que sustenta o status quo. Tristes tempos!

Na contramão desse processo, ainda é possível, na universidade pública, pensar as contradições que movem nossa realidade profundamente desigual. Ainda é possível ler, refletir, pensar os caminhos da construção de um projeto que transforme essa realidade, revitalizando o pensamento crítico e a utopia. Nesse movimento, o Dossiê é um convite à reflexão sobre nossa condição urbana a partir dos escritos de Henri Lefebvre.

Nesse contexto, ler Lefebvre é imperativo.

Ana Fani Alessandri Carlos César Simoni Santos Glória Anunciação Alves

\section{revista}

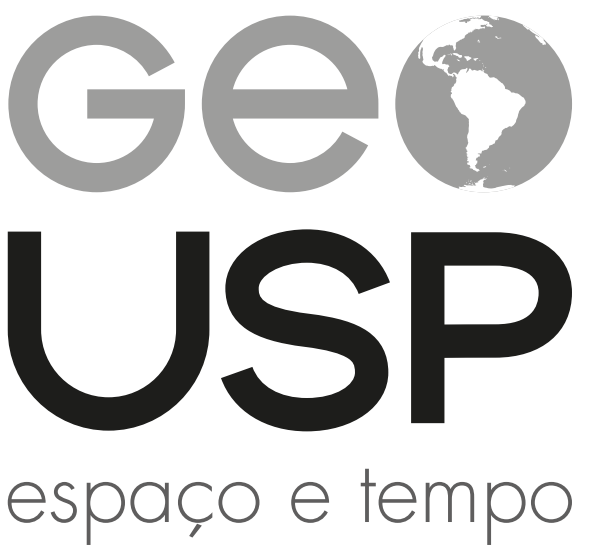

Volume $23 \bullet n^{\circ} 3(2019)$

ISSN 2179-0892 